\title{
PERCERÇÃO DO USUÁRIO NA ESCOLHA DE PLACAS CERÂMICAS PARA O AMBIENTE RESIDENCIAL
}

\author{
NASCIMENTO, Izabel C. M. O. (1); \\ MONT'ALVAO, Cláudia (2) \\ (1) Universidade Federal do Maranhão, Mestranda \\ e-mail:izabel.nas13@gmail.com \\ (2) Pontifícia Universidade Católica do Rio de Janeiro - PUC-Rio, Doutora \\ e-mail:cmontalvao@puc-rio.br
}

\begin{abstract}
RESUMO
Este artigo apresenta uma etapa de uma pesquisa qualitativa sobre aspectos subjetivos, considerados pelo usuário como ideais, e que influenciam sua percepção sobre um produto. Esta avaliação se fez com base na ergonomia do produto e na percepção do usuário de placas cerâmicas, considerando a aplicação deste material no ambiente residencial. Foi testado o roteiro determinado para uma entrevista semiestruturada, e a adaptação, feita pelo pesquisador, sobre a técnica de fotoelicitação. Percebeu-se a necessidade de ajustes no roteiro da entrevista, mas o uso de amostras, no lugar de fotografias, se mostrou eficaz com os objetivos da pesquisa.
\end{abstract}

Palavras chave: percepção do usuário; placa cerâmicas; ambiente residencial.

\begin{abstract}
This article presents the first step of research about subjective aspects, considered by the user as ideals, and that influence their perception about a product. This evaluation was made based on the ergonomics of the product and the user's perception of ceramic plates, considering the application of this material in the residential environment. It was tested the script for a semi-structured interview, and the researcher's adaptation of the photo-elicitation technique. It was noticed the need for adjustments in the interview script, but the use of samples, instead of photographs, was efficient with the research objectives.
\end{abstract}

Keywords: user's perception; ceramic plate; residential environment.

\section{INTRODUÇÃO}

Muitos trabalhos discutem o ambiente construído de empresas e espaços públicos e a relação entre as pessoas, o ambiente e a atividade desempenhada nele. Partindo do entendimento de que a casa também possui espaços onde ocorrem interações humanotarefa-ambiente, uma atenção a estes locais e aos materiais aplicados neles auxiliará em um melhor desempenho dessa edificação. A ergonomia ocupa-se desta análise e auxilia na produção de espaços mais adaptados às atividades do homem melhorando a sua produtividade (VILLAROUCO; ANDRETO, 2008). Uma análise voltada ao ambiente deve levar em consideração tanto os seus elementos tangíveis (físicos) como os intangíveis, ou seja, que envolvem a percepção do usuário (TAVARES et al., 2016). A percepção que os 


\section{(n) $^{\text {enac }}$}

usuários possuem sobre o ambiente influencia na escolha dos materiais a serem empregados nos espaços da moradia, e consequentemente nas atividades desempenhadas nela. Placas cerâmicas que aparentam ter atributos, mas que durante seu uso demonstram que não os possuem, comprometem o desempenho que se espera do ambiente onde elas foram assentadas. O termo placa cerâmica é usado neste trabalho em lugar da palavra revestimento cerâmico, tanto no que se refere a placas aplicadas ao piso quanto à parede, como os azulejos, por exemplo, partindo do entendimento de que revestimento cerâmico engloba mais de um produto, pois é o "conjunto formado pelas placas cerâmicas, pela argamassa de assentamento e pelo rejunte" (ASSOCIAÇÃO BRASILEIRA DE NORMAS TÉCNICAS, 1997), sendo mais correto chamar de "placas cerâmicas para revestimento" (ASSOCIAÇÃO BRASILEIRA DE NORMAS TÉCNICAS, 1997).

Esta pesquisa, que tem como objeto de estudo as placas cerâmicas para moradia, considera a sua aplicação em habitações destinadas à população de baixa renda, e consequentemente a habitação de interesse social. Desde a década de 40 , visando garantir que pessoas de baixa renda pudessem realizar o "sonho da casa própria", tem sido implantados programas de construção habitacionais através de programas governamentais (BONDUKI, 1994; AZEVEDO e ANDRADE, 1982). Este acesso a moradia tem sido possível através de financiamentos subsidiados pelo poder público e pela redução dos juros (CAIXA ECONÔMICA FEDERAL, 2017). O mesmo se dá com o programa em vigência, lançado em 2009, o Programa Minha Casa Minha Vida - PMCMV. Ele foi idealizado considerando as áreas urbanas e rurais, e prevê padrões de edificações separas por faixa de renda salarial. Estas subdivisões organizam-se em: faixa 1, para famílias com renda de até mil e oitocentos reais; faixa 1,5, para famílias com renda de até dois mil e seiscentos reais; faixa 2, para famílias com renda bruta de até quatro mil reais; e faixa 3 , para famílias com renda bruta de até sete mil reais (CAIXA ECONÔMICA FEDERAL, 2017).

Em São Luís foram concluídos pelo PMCMV seis empreendimentos, inseridos na faixa 1, e quatro estão em andamento. Eles dividem-se entre empreendimentos de casa e apartamentos, sendo maior o número de construções de casas. Apesar da oportunidade de adquirir a casa própria ser positiva, os futuros usuários não tem controle sobre as decisões de projeto, eles não são consultados sobre decisões construtivas e de acabamentos. A tomada de decisão por parte dos incorporadores e gestores públicos, sem a opinião dos futuros moradores é um descaso com os compradores (SANTOS 2012). Todas as regiões do Brasil costumam receber o mesmo projeto para as habitações de interesse social, em uma padronização de construções que desconsideram as particulares de cada clima, cultura e comunidade. Eles recebem empreendimentos que obedecem a um mesmo programa de necessidade, feito para responder ao mínimo das exigências definidas pela Caixa Econômica Federal, refletindo em habitações pequenas e com poucos cômodos. Os beneficiários, já comprometidos com as parcelas do financiamento, em muitos casos, não possuem condições de executar melhorias, e quando o tem, limitam-se a repintura de paredes e troca da placa cerâmica de piso.

No caso das placas cerâmicas, objeto desta pesquisa, se trata de um produto com função a de proteção do ambiente construído, mas também na configuração da identidade de um lugar. Este produto surgiu a 8.000 a. C., no Médio Oriente, como opção para o armazenamento de alimentos, e quando transformado em placas, ganhou a função de proteção dos abrigos (BORGES, 2008) sendo então usado para revestimentos. Este avanço se deu pelas suas características de ser resistente, impermeável, fácil de fazer e de depender apenas da matéria prima local (ANFACER, 2017). No Brasil sua importação se deu pelos portugueses, a partir do século XVI, e a formação de um mercado deste produto ocorreu a partir da chegada de alguns ceramistas italianos que se mudaram para o país (BORGES, 2008). Além das funções de proteção, este produto dá personalidade ao ambiente e a superfície onde é aplicada, o que ajudou na difusão do uso deste produto. 
Em São Luís os motivos para a consolidação do uso deste material foi a mesma no Brasil, e principalmente por ser uma solução para proteger as fachadas e pisos, devido a cidade possuir intensas chuvas, e como uma solução estética para Igrejas e casarões da cidade (SILVA, 2005). Ainda hoje a placa cerâmica é relacionada a proteção e personalização, de edifícios comerciais, institucionais e de moradias, e o mercado possui uma variedade de opções, desde aquelas presentes em qualquer loja do Brasil, até peças imitando os antigos ladrilhos e azulejos das edificações tradicionais. Existem também produtos que imitam outros materiais e possuem a vantagem de demandarem menor manutenção que os materiais originais, como por exemplo, madeira, concreto, mármore, etc. Esta infinidade de opções existentes no mercado, opondo-se a repetição do uso padronizado de placas nas moradias do PMCMV, levou ao questionamento sobre quão contemplados estes consumidores-usuários estão com as placas assentadas nas unidades residenciais.

Para isso, este trabalho relata o teste de formulário, materiais e técnicas de uma pesquisa qualitativa que busca compreender o que moradores de empreendimentos do Programa Minha Casa Minha, faixa 1, localizados em São Luís do Maranhão, consideram como sendo a placa cerâmica ideal para a sua própria residência. Considera para isso que a encolha inadequada de uma placa cerâmica pode interferir diretamente na ergonomia do ambiente construído, ou seja, na "interação do usuário, com o ambiente, o mobiliário, os objetos e a tarefa dentro de um mesmo sistema", (OLIVEIRA; MONTÁLVÃO, 2015), afetando assim o bom desempenho das atividades em seu interior. Esta pesquisa reflete sobre esta interação, do morador com a placa cerâmica assentada em sua moradia, considerando quem usará e como ocorrerá o uso do produto, questionando sobre ele responder ou não às expectativas de cada morador (MORAES, 2004). Para esta análise foi realizada uma entrevista semiestruturada, onde o pesquisador se dirigiu a casa de cada entrevistado, utilizando-se uma das etapas do design Contextual (HOLTZBLATT e BEYER, 2014), a inquirição contextual, visando ampliar a coleta de dados subjetivos e aspectos pessoais que envolvem a escolha e utilização de placas cerâmicas de piso no ambiente residencial. Concomitante a entrevista, foi também realizada uma técnica que tomou como base a foto-elicitação (BANKS, 2009), mas que foi adaptada pela substituição das fotografias por amostras de placas cerâmicas, anteriormente definidas na pesquisa exploratória, para entendimento da ordem de preferência que cada morador teria, caso fosse comprar uma daquelas placas para colocação em sua casa.

Este artigo estrutura-se em três tópicos visando delinear o entendimento sobre a a ergonomia do produto e a percepção que o usuário possui sobre as placas cerâmicas, o método utilizado para compreensão das expectativas que são criadas sobre a aplicação do produto e sua eficiência no desempenho de atividades, e a relação que o usuário faz, no momento da escolha, sobre o ambiente, as pessoas que o utilizarão e a tarefa que será desenvolvida naquele espaço. A primeira parte trata da atenção que a ergonomia tem sobre os aspectos físicos e cognitivos do ambiente, entendendo que estes elementos influenciam na relação humano-tarefa-ambiente. $E$ também como a percepção do usuário é definida a partir destas variáveis, levando esta reflexão para o ambiente de moradia e especificamente às placas cerâmicas nela assentadas. A segunda parte discorre sobre a pesquisa e a técnica de entrevista semiestruturada, realizada com estabelecimento antecipado de um roteiro e com o auxílio da técnica de foto-elicitação, explicando contudo a substituição das fotografias por amostras de placas cerâmicas. Na terceira parte é feita a narrativa do comportamento e comentários dos entrevistados, organizando as informações mais relevantes e discorrendo sobre cada uma delas. Nesta etapa, são explicadas as alterações consideradas necessárias para reformulação do roteiro a ser utilizado no seguimento desta pesquisa, na fase de coleta de dados. Ao final são levantados questionamentos, não sobre a escolha realizada pelos futuros usuários, mas sobre adequações que devem ser feitas a fim de garantir escolhas que contribuam para a melhoria do desempenho das atividades que serão desenvolvidas em cada ambiente residencial. 


\section{ERGONOMIA DO PRODUTO E PERCEPÇÃO DO USUÁRIO DE PLACAS CERÂMICAS}

O estudo da ergonomia de um ambiente preocupa-se com o entendimento das tarefas desempenhadas no interior de um espaço construído e da relação que elas terão com as pessoas que as desempenham, ou seja, um estudo da interação homem-tarefa-ambiente. Ela tem como objeto de estudo essa tríade onde a ergonomia funciona como um sistema com interfaces onde são trocados dados físicos e subjetivos entre o homem, o produto e o ambiente, ocasionando no desenvolvimento de uma atividade (IIDA, 2005). Muitos estudos enfocam em atividades realizadas no ambiente industrial e comercial, visando a saúde dos funcionários e a produtividade, mas um outro ambiente deve ser também estudado, a casa. Ela é cenário de uma infinidade de tarefas diárias com significados que, assim como outras construções, transcendem suas características técnicas e físicas, pois estão também impregnadas se sentimentos e aspectos subjetivos (TAVARES et al., 2016) que influenciarão na relação que o indivíduo tem com o ambiente no desempenhar de atividades cotidianas. Entendendo que uma casa é construída para pessoas, faz-se necessário um entendimento sobre elas, sobre os elementos que constituem este espaço e sobre como elas irão interagir com estes elementos. É preciso que se projete para as pessoas dentro de suas peculiaridades e não para como projetistas gostariam que elas se comportassem (NORMAN, 2013). Os materiais empregados em uma casa devem levar em consideração a maneira como os seus moradores os percebem, e como eles entendem que cada produto trabalha, ou seja, devem considerar a percepção que cada usuário tem sobre a experiência de uso de cada produto.

A percepção que um indivíduo possui sobre qualquer elemento físico, ou mesmo abstrato, advém de experiências que ele viveu e da maneira como ele as reteve na memória. Ela não se limita a capacidade de se enxergar algo, mas às inter-relações que este indivíduo faz quando exposto a este estímulo (NUNES, 2015). A percepção do usuário influencia diretamente na relação que ele tem com o ambiente, podendo ser atraente para sua permanência e confortável em seu uso, tendo como resultado sua satisfação ou não (TAVARES et al., 2016). A percepção negativa pode ocorrer a partir de ambientes projetados com dimensões e posicionamentos diferentes daqueles considerados ideais por quem utiliza o lugar; pela escolha errada de mobiliários, iluminação e cores; e pelo assentamento de placas cerâmicas, conforme o entendimento do usuário, inadequadas às ações que serão desempenhadas e às sensações que o usuário gostaria de sentir. Uma placa cerâmica deve ter qualidades técnicas, visuais e sensoriais que deixem claro ao usuário qual será o desempenho que ela terá quando aplicada a uma residência, ou seja, precisa garantir o fácil entendimento de sua aplicabilidade, bem como do seu assentamento. Ela deve apresentar de forma clara suas qualidades técnicas ergonômicas (IIDA, 2005) e também aquelas subjetivas, garantindo uma satisfação ao final da aplicação e utilização do produto que, apesar de particulares a cada usuário, refletirão no bom desempenho das atividades no interior de uma moradia.

Este trabalho trata da investigação sobre a dos percepção dos moradores de unidades habitacionais dos empreendimentos do Programa Minha Casa Minha Vida. Ela não irá investigar aspectos físicos do ambiente construído, mas a percepção que estes moradores têm sobre o espaço habitado considerando a placa cerâmica aplicada ao piso. Esta percepção se estende para além das sensações, pois advém do significado que é dado à estas informações fornecidas pelos nossos sentidos (NUNES, 2015). Ela resulta da experiência e como tal, vem carregada de uma reflexão de resultados e consequências já vivenciadas e que são lembradas como satisfatórias ou frustrantes (NORMAN, 2013). 
Assim, o estudo da ergonomia que leva em consideração a percepção do usuário, não diz respeito apenas ao produto de forma isolada, o seu desempenho no ambiente em que é aplicado (considerando variantes técnicas exigidas em normas e fornecidas pelos fabricantes), mas também as variantes cognitivas que cada usuário irão permitir o seu julgamento de desempenho, tornando mais completa a avaliação sobre um produto. Por isso, a produção de uma placa cerâmica deverá considerar, além das características do produto pensadas na fábrica, aquelas que são consideradas pelo morador, pois o usuário avaliará o desempenho do ambiente com base em aspectos que ele acredita que os produtos possuem. Uma casa deve ser pensada e projetada a partir do conhecimento dos seus futuros moradores e de suas expectativas, entendendo que a eficiência de um ambiente construído depende também do entendimento das atividades que serão desempenhadas em seu interior e da diversidade de usuários, possibilitando respostas às necessidades funcionais e psicológicas de cada morador, e garantindo a eficiência dos produtos nela inseridos e utilizados no decorrer das atividades (VILLAROUCO; ANDRETO, 2008).

\section{MÉTODO PARA ENTENDIMENTO DAS EXPECTATIVAS SOBRE O PRODUTO}

Esta pesquisa tem caráter qualitativo e tem enfoque no entendimento de aspectos subjetivos importantes para a percepção que beneficiários do programa Minha Casa Minha Vida, na cidade de São Luís - MA, tem sobre a placa cerâmica para revestimento de piso, assentadas nas suas unidades habitacionais. Como parte da investigação foi realizada uma fase de teste de formulário e técnicas utilizadas durante a entrevista, com o objetivo de entender os possíveis resultados e erros do formato pré-estabelecido, permitindo que estes sejam corrigidos e readequados para utilização na fase de coleta de dados (MARCONI \& LAKATOS, 1996). Para o pré-teste foram entrevistados aleatoriamente um total de 5 moradores, devido a amostragem ser do tipo não probabilística intencional (GIL, 2008), onde os entrevistados são ouvidos até a repetição do discurso. Neste grupo entrevistado foram contemplados três empreendimentos entregues na cidade, compreendendo 2 (dois) moradores do Residencial Santo Antônio, 2 (dois) do Residencial Ribeira e 1 (um) Residencial Amendoeira.

A entrevista utilizada foi do tipo semiestruturada, pois permitiu a realização com informalidade, onde entrevistados e pesquisador puderam inserir assuntos não previstos mas que são pertinentes à pesquisa. O ambiente de realização das entrevistas foi a casa de cada entrevistado, seguindo a etapa de Inquirição Contextual, uma das fases utilizadas pelo Design Contextual (HOLTZBLATT e BEYER, 2014), pois a pesquisa visa coletar a maior quantidade de dados subjetivos referentes a percepção que os moradores possuem sobre as placas de piso, e a realização no ambiente onde o produto é utilizado traz memórias de uso e experiências dos seus usuários. Inserida na estrutura da entrevista semiestruturada foi utilizada a técnica de foto-elicitação, também como forma de trazer à tona mais comentários e reflexões (BANKS, 2009) sobre a utilização do piso. Devido resultados da fase exploratória, anteriormente realizada, onde usuários foram observados durante a compra de placas cerâmicas, a utilização das fotografias proposto por Banks (2009) foi substituída pelo uso de amostras de placas, pois foi percebida a relevância que a textura de cada superfície possui como critério de julgamento sobre a experiência que este produto trará quando assentado no ambiente edificado.

Como resultado, foram selecionadas amostras de 8 tipos de piso, escolhidas também após fase exploratória da pesquisa de visita as principais lojas do mercado de placas cerâmicas de São Luís e de visita aos empreendimentos. Devido ao público-alvo da pesquisa ser de moradores de empreendimentos da faixa 1 programa, ou seja, a faixa de menor renda, 4 (quatro) amostras foram escolhias por possuírem características comuns quando 
observados os produtos mais divulgados pelas lojas e por estarem em promoção, 1 amostra consistiu de um produto caro no mercado, mas com características bem diferenciadas de textura, acabamento, espessura e cor, e 3 (três) amostras possuíam proximidade com características encontradas nos 3 empreendimentos visitados (Tabela 1).

Tabela 1 - Informações sobre as amostras.

\begin{tabular}{|c|c|c|c|}
\hline AMOSTRA & TIPO & ACABAMENTO & OBSERVAÇÖES \\
\hline a & Piso branco esmaltado & Liso & $\begin{array}{c}\text { Semelhante ao encontrado no } \\
\text { Residencial Ribeira }\end{array}$ \\
\hline b & Piso branco esmaltado & Rajado & $\begin{array}{l}\text { Semelhante ao encontrado no } \\
\text { Residencial Santo Antônio }\end{array}$ \\
\hline C & Piso branco esmaltado & Textura granulada & $\begin{array}{l}\text { Semelhante ao encontrado no } \\
\text { Residencial Amendoeira }\end{array}$ \\
\hline d & $\begin{array}{l}\text { Porcelanato bege } \\
\text { polido }\end{array}$ & Liso & $\begin{array}{c}\text { Comum no mercado e em } \\
\text { promoção }\end{array}$ \\
\hline e & $\begin{array}{l}\text { Porcelanato cinza } \\
\text { acetinado }\end{array}$ & Liso & $\begin{array}{l}\text { Comum no mercado e em } \\
\text { promoção }\end{array}$ \\
\hline f & $\begin{array}{c}\text { Piso bege } \\
\text { antiderrapante }\end{array}$ & $\begin{array}{l}\text { Semelhante a } \\
\text { pedra }\end{array}$ & $\begin{array}{l}\text { Comum no mercado e em } \\
\text { promoção }\end{array}$ \\
\hline g & $\begin{array}{c}\text { Piso cinza } \\
\text { antiderrapante }\end{array}$ & $\begin{array}{l}\text { Desenho } \\
\text { geométrico }\end{array}$ & $\begin{array}{c}\text { Comum no mercado e em } \\
\text { promoção }\end{array}$ \\
\hline h & $\begin{array}{l}\text { Porcelanato canela } \\
\text { retificado }\end{array}$ & Textura de madeira & $\begin{array}{c}\text { Produto com preço elevado no } \\
\text { mercado }\end{array}$ \\
\hline
\end{tabular}

Fonte: Elaborada pela autora (2017).

O roteiro da entrevista foi estruturado prevendo sua realização em dois momentos: o primeiro preenchendo os dados pessoais, dados do piso encontrado, perguntas binárias e pesquisa de satisfação; e o segundo, uma entrevista com as amostras do piso. O início da entrevista destinou-se ao levantamento de dados sobre o piso existente (textura, cor, tamanho, tipo e tamanho), sobre a vontade (ou não) de mudar o piso existente ou sobre o piso já trocado, e o nível de satisfação que o entrevistado considera para o piso e para o ambiente em que ele está assentado. Seguido a isto foram expostas as amostras ao voluntario da pesquisa.

Para a organização da ordem de preferência foi utilizada uma superfície em feltro preto, com desenho semelhante a uma tabela, onde cada espaço recebeu uma numeração de 1 a 8 , sendo assim possível uma visualização mais clara da ordem que cada usuário definiria para as amostras (Figura 1). Nesta etapa foi explicado aos entrevistados sobre a necessidade de registro fotográfico do processo de ordenamento das placas, enfatizando que as fotos não mostrariam seus rostos, mantendo assim a confidencialidade do estudo. Foi explicado também sobre a inexistência de uma ordem 'certa' para as amostras, visto que o principal objetivo seria conhecer as preferencias individuais de cada participante.

Figura 1 - Amostras de piso e superfície para ordenação da preferência.

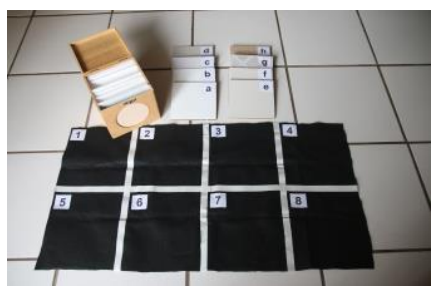

Fonte: Elaborada pela autora (2017). 


\section{RESULTADOS}

Todas as entrevistas foram iniciadas com a leitura do Termo de Consentimento Livre e Esclarecido - TCLE, explicando a pesquisa, seus objetivos e procedimentos, bem como os riscos e benefícios da sua realização e participação. Também foram feitos esclarecimentos sobre a confidencialidade do estudo e sobre a participação ser voluntária, ficando claro aos entrevistados da inexistência de penalidades advindas da recusa ou desistência na participação. Ao final da leitura foi feita a pergunta sobre concordarem em participar, o que foi dado continuidade somente após a concordância verbalizada de cada participante, bem como após a assinatura do termo, pelo participante e pelo pesquisador, onde cada morador deu anuência à realização da entrevista. O TCLE foi impresso em duas vias, ficando uma via assinada com o participante e a outra com o pesquisador.

Seguido a isso, foi dado início à entrevista semiestruturada e à contagem do tempo total de entrevista, que variou entre vinte e trinta minutos. Em um primeiro momento foi feito pelo pesquisador o registro do nome do empreendimento e o primeiro nome do participante, a medição do tamanho da placa cerâmica encontrada no local, e de dados referentes a cor, textura, e tipo de produto. A etapa de "perguntas binárias"1, apesar de assemelharem-se à perguntas sem grande abrangência de resposta (do tipo sim ou não), nesta entrevista funcionaram com ponto de partida para a explanação do assunto e controle do encaminhamento da entrevista sem que o conteúdo fugisse aos objetivos propostos. Como todos os pisos encontrados foram aqueles entregues pela construtora, foi feito o registro apenas de informações sobre a vontade de mudar ou não o piso. Quanto às respostas sobre o nível de satisfação, elas reforçaram os discursos anteriores e trouxeram à pesquisa o entendimento de que a opinião sobre um produto se difere da opinião sobre a estética do ambiente em que ele está aplicado. A Tabela abaixo organiza algumas informações descritas pelos participantes, que foram organizados em sequência numérica, preservando assim a identidade deles (Tabela 2).

Tabela 2 - Dados da primeira fase da entrevista semiestruturada.

\begin{tabular}{|c|c|c|c|c|c|c|c|c|}
\hline \multirow[t]{2}{*}{ № } & \multirow[t]{2}{*}{ RESIDENCIAL } & \multicolumn{3}{|c|}{ PISO ENCONTRADO } & \multirow[t]{2}{*}{ GOSTA? } & \multirow[t]{2}{*}{$\begin{array}{c}\text { QUER } \\
\text { MUDAR? }\end{array}$} & \multicolumn{2}{|c|}{$\begin{array}{l}\text { NIVEL DE } \\
\text { SATISFAÇÃOO }\end{array}$} \\
\hline & & tamanho & cor & textura & & & piso & aparência \\
\hline 1 & Santo Antônio & $35 \times 35$ & branco & rajado & não & $\operatorname{sim}$ & 2 & 2 \\
\hline 2 & Santo Antônio & $32 \times 32$ & branco & rajado & não & $\operatorname{sim}$ & 0 & 1 \\
\hline 3 & Ribeira & $32 \times 32$ & branco & liso & não & $\operatorname{sim}$ & 2 & 2 \\
\hline 4 & Ribeira & $32 \times 32$ & branco & liso & - & $\operatorname{sim}$ & 3 & 2 \\
\hline 5 & Amendoeira & $32 \times 32$ & cinza & granulado & sim & não & 2 & 5 \\
\hline
\end{tabular}

Fonte: Elaborada pela autora (2017).

Os entrevistados de número 1 e 2, moradores do Residencial Santo Antônio, possuíam o mesmo piso, diferindo-se apenas pelo tamanho das placas. Ambos se queixaram da dificuldade de manter a casa limpa devido o piso em pouco tempo já aparentar estar sujo. $O$ primeiro relatou que "o piso arranha e suja muito" endossando que a sujeira "gruda e não sai". O segundo relatou que o piso já apresentava rachaduras quando recebeu e que pedaços do esmalte fica se desprendendo da superfície, descrevendo que "ele tá tipo saindo... não sei se é a tinta... não sei o que que é... mas muito arranhado... viu... muito arranhado". Também afirma que "já passou vários produtos para tirar as manchas, mas elas não saem". O entrevistado de número 3 , morador do Residencial Ribeira, possui em sua

\footnotetext{
1 Termo definido pelo pesquisador.
} 


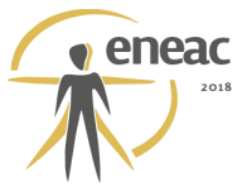

moradia um piso diferente daquele descrito pelos entrevistados anteriores, mas tem eu seu discurso a mesma reclamação sobre a sujeira afirmando que "por mais que limpe o piso está sempre sujo". Contudo, o entrevistado de número 4, apesar de possui o mesmo piso, não tem queixas sobre ele, e disse que vai mudar no ano seguinte porque pretende reformara a casa. Já o morador do Residencial Amendoeira, entrevistado de número 5, relatou que por enquanto não pretendia mudar o piso, "que ele não é ruim" e que quanto à limpeza basta" passar uma água sanitária nele e tá bom". O piso neste empreendimento difere-se dos demais em cor e textura.

Quanto ao nível de satisfação do piso, foi solicitada uma nota de 0 (zero) a 5 (cinco), considerando para o zero que o usuário está muito insatisfeito, e 5 que ele está muito satisfeito. Os quatro primeiros entrevistados deram notas sob a mesma justificativa, sendo a avaliação da satisfação quanto ao piso advinda do julgamento dele como um produto de má qualidade, devido à presença rachaduras, e a avaliação da satisfação quanto a aparência resultante da impressão que o piso dá de estar sempre sujo. Como pode ser vista na Tabela 2 , as notas individuais são diferentes, mas todos consideraram o piso como regular. No caso do entrevistado de número 5 , quando questionado sobre o nível de satisfação, preferiu dar a nota 2 para o piso, afirmando "não ter conhecimento dele, se ele é bom". Entretanto, para a aparência que ele dá ao ambiente considerou a nota máxima de satisfação.

Um segundo momento da entrevista utilizou-se das amostras das placas cerâmicas, onde os entrevistados organizaram-nas seguindo sua própria ordem de preferência, o que resultou nos dados abaixo (Tabela 3).

Tabela 3 - Dados da entrevista com amostras do piso.

\begin{tabular}{|c|c|c|c|c|c|c|c|c|c|c|c|}
\hline \multirow{2}{*}{ № } & \multirow{2}{*}{ RESIDENCIAL } & \multirow{2}{*}{$\begin{array}{c}\text { LEU A } \\
\text { ETIQUETA? }\end{array}$} & \multicolumn{8}{|c|}{ PREFERÉNCIA DECLARADA } & \multirow[b]{2}{*}{ OBSERVAÇÕES } \\
\hline & & & 1 & 2 & 3 & 4 & 5 & 6 & 7 & 8 & \\
\hline 1 & Santo Antônio & não & $d$ & $f$ & a & - & - & - & - & - & $\begin{array}{l}\text { Não ordenou as peças } \\
\text { apenas definiu o que } \\
\text { preferia para a casa e } \\
\text { para o banheiro. }\end{array}$ \\
\hline 2 & Santo Antônio & não & $d$ & e & $b$ & a & $f$ & $\mathrm{~h}$ & c & $g$ & $\begin{array}{c}\text { Juntou grupos e ordenou } \\
\text { preferência entre eles } \\
\text { sendo: } 4 \text { para dentro de } \\
\text { casa e } 4 \text { para a área } \\
\text { externa. }\end{array}$ \\
\hline 3 & Ribeira & $1 \mathrm{vez}$ & c & $g$ & $\mathrm{~h}$ & $f$ & b & $d$ & e & a & $\begin{array}{l}\text { Colocou a opção “a” } \\
\text { como última opção. }\end{array}$ \\
\hline 4 & Ribeira & não & a & b & d & e & $f$ & $\mathrm{~h}$ & C & $g$ & $\begin{array}{c}\text { Juntou grupos e ordenou } \\
\text { preferência entre eles } \\
\text { sendo: } 4 \text { para dentro de } \\
\text { casa e } 4 \text { para a calçada, } \\
\text { banheiro, muro e não } \\
\text { compraria. A opção "a" } \\
\text { foi a primeira } \\
\text { considerada por ele. }\end{array}$ \\
\hline 5 & Amendoeira & $\operatorname{sim}$ & $d$ & $b$ & $\mathrm{e}$ & $f$ & a & $\mathrm{h}$ & C & $g$ & $\begin{array}{l}\text { A opção "c" ficou em } \\
\text { penúltimo lugar. }\end{array}$ \\
\hline
\end{tabular}

Fonte: Elaborada pela autora (2017).

Esta etapa, pelo seu caráter mais interativo, semelhante à uma dinâmica, contribuiu na coleta de mais detalhes, pois os entrevistados mostraram-se mais 'relaxados' e espontâneos e, em alguns momento, até chamando outros familiares para participar. O entrevistado de número 1 preocupou-se com qual cômodo da casa deveria ser pensado. Informado que ele poderia escolher qualquer um, optou pelo banheiro escolhendo o piso "f" para a área do box, mas preferindo um piso mais liso, piso "a", para as outras áreas do banheiro. Já havia 
decidido não escolher mais nenhum, por não gostar das opções, quando olhou que havia uma amostra de porcelanato afirmando em seguida que "esses aqui tão usando muito... tem uma casa ali que eles botaram esse... eu botaria esse na casa toda". Ao final não quis escolher mais nenhuma peça e pôs em ordem apenas os três que havia gostado.

O entrevistado de número 2 teve opinião semelhante ao anterior colocado as opções de porcelanato em primeiro e segundo lugar. Considerou para isso que ele era bonito, mas que também seria fácil de limpar. Contudo, quando ordenou as demais opções, colocou em terceira opção o piso de letra "b", semelhante ao existente em sua casa, seguindo o pensamento daquele produto que seria bonito. Este mesmo piso, quando considerada a satisfação de uso, havia recebido nota zero, considerando que o usuário estaria totalmente insatisfeito com o produto. Este entrevistado separou a ordem de preferência em dois grupos sendo os números de 1 a 4 , para as placas a serem colocadas na parte interna da casa e os números de 5 a 8 para materiais destinados a área externa.

O entrevistado de número 3 , assim que iniciou a dinâmica, reconheceu a semelhança do piso "a" com aquele assentado em sua moradia, e logo o posicionou como a última opção na ordem de preferência. Preferiu a colocação do piso "c", e teve como imaginário o ambiente da sala de estar, chamando então seu filho: "já imaginou? A sala toda desse jeito? (coloca a amostra "c" no chão)... ó aqui P..... (mostra para o filho)... tu já imaginou se a sala fosse toda desse jeito? ... era mais bonita, não era?'. Questionado sobre o porquê da preferência por este piso disse que achou ele bonito, que ele não seria tão fácil de escorregar e que seria fácil de limpar. A opção por um piso não escorregadio foi bem presente, pois as amostras colocadas em seguida, de 2 a 4, foram de placas com as superfícies mais antiderrapantes.

O entrevistado de número 4 , que havia afirmado trocar o piso apenas devido a reforma que pretendia fazer, considerou a amostra "a", semelhante à encontrada em sua casa, como primeira opção afirmando achar bonito apesar de não ser porcelanato. Questionado sobre o porquê da escolha disse que o piso existente na casa do pai era semelhante àquele, e que ele achava bonito e que gosta desse tipo de piso, a diferença que faria se comparado ao piso existente em sua casa é que ele, assim como o pai, colocaria em diagonal, ao invés de alinhado a parede.

O entrevistado de número 5 , apesar de afirmar gostar do piso existente em sua casa e de não ter a intenção de trocá-lo, colocou a amostra "c", semelhante à já assentada, em penúltimo lugar, e preferiu o porcelanato polido frente ás outras opções. Durante esta etapa não expos as razões para cada ordem escolhida, mas quando questionado sobre o porquê de preferir a amostra " $\mathrm{d}$ ', declarou: "Esse eu achei mais bonito... assim tem ... ele brilha... ele é brilhante".

As informações coletadas contribuíram na reestruturação da metodologia com a inserção da filmagem no momento da entrevista com amostras do piso, uma vez que as fotos são estáticas, mesmo com a gravação de voz em alguns momentos, não fica claro para quais amostras estão sendo direcionados os comentários, e por isso algumas informações não puderam ser coletadas. O discurso dos entrevistados ao longo das entrevistas demonstrou a importância de se inserir no roteiro os questionamentos sobre eles gostarem ou não da placa existente, comprarem ou não se ela estivesse disponível na loja, e se a indicariam ou não a um amigo, garantido que estes assuntos seriam abordados em todas as entrevistas futuras. Como resultado foi organizado um novo roteiro a ser preenchido pelo pesquisador, mantendo-se o campo destinado a entrevistas com usuários que já trocaram o piso, para entendimento da satisfação de cada um quando usuários de produtos escolhidos por eles mesmos (Figura 2). A etapa da entrevista que se utilizou de amostras de placas cerâmicas permaneceu inalterada, pois funcionou para a coleta dos dados a que se propôs, bem como aumentou melhorou o interesse do entrevistado às questões abordadas dada a sua característica interativa. 


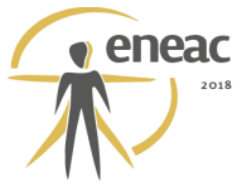

Figura 2 - Roteiro final da coleta de dados.

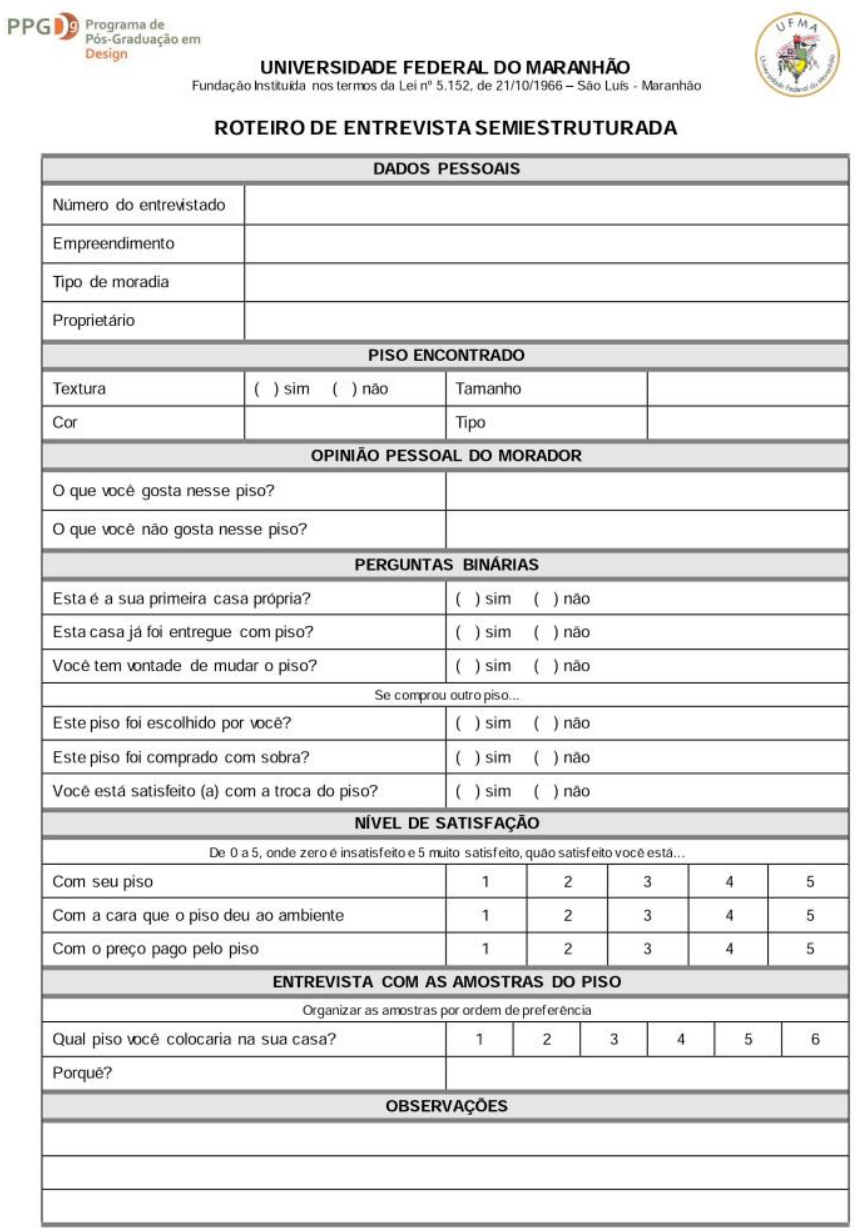

Universidade Federal do Maranhăo(UFMA)-Centro de Gências Exatas e Tecnologias (CCET)

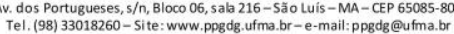

Fonte: Elaborada pela autora (2017).

\section{CONSIDERAÇÕES FINAIS}

Apesar de se tratar de uma fase preliminar da pesquisa, esta fase demonstrou a importância de entender a maneira como o produto, e o espaço onde ele será aplicado, é entendido pelo consumidor. Um dos elementos que evidente foi o julgamento do que cada um considera bonito, seja no entendimento da "aparência de sujo" que o piso existente dá, ou pela beleza considerada para colocação de algumas amostras como primeira opção. Este raciocínio soma-se à experiência de alguns usuários, quando o critério de escolha passa a ser a beleza de um material semelhante aplicado na casa de algum conhecido, seja um parente, no caso do entrevistado de número 4, ou um vizinho, no caso do entrevistado de número 1.

Algumas escolhas como a do entrevistado de número 2 (que priorizou a placa cerâmica semelhante àquela já existente frente a opções semelhantes, mesmo considerando seu grau satisfação como zero), levaram à reflexão sobre os riscos que a estética traz para percepção real de um produto, quando ela omite a real experiência que aquele usuário terá com o produto. Esta priorização da beleza do produto poderá levar o usuário a comprar um produto para substituição do existente, mas que não irá melhorar a interação dele com o 


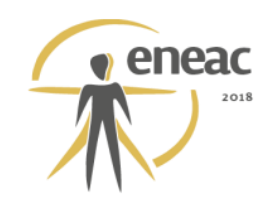

ambiente, pois a experiência do usuário manter-se-á insatisfatória. Escolhas como a do entrevistado de número 3 , que escolheu uma amostra esmaltada com a expectativa dela não ser escorregadia, demonstra a importância de se experimentar os produtos antes da compra, de se entender se ele possui os atributos esperados e se responderá às expectativas. Isso aponta, ainda, que a simples exibição das peças nas lojas ainda não é suficiente para o esclarecimento dessas diferenças e nem sempre permite o entendimento correto por parte do usuário.

Muitas escolhas foram realizadas por critérios pessoais, o que demonstrou a importância de primeiro se finalizar a coleta de dados, para só então realizar afirmações sobre a percepção do usuário e o seu grau de satisfação, quanto ao desempenho de suas atividades e dos ambientes de moradia revestidos com placas cerâmicas.

Considerando-se que a venda de placa cerâmicas já se dá em um mercado já consolidado, e que ela se faz sem a necessidade de acompanhamento de um profissional para orientar o usuário sobre a escolha, a maneira de se comunicar com este consumidor deve ser mais próxima daquela que é comum a ele, permitindo que o desempenho de suas atividades no ambiente de moradia, no caso desta pesquisa, ou mesmo em qualquer outro ambiente em que uma pessoa necessite desempenhar uma atividade, não seja prejudicada pela má comunicação entre aquilo que se espera e como realmente o produto trabalha. Considerar a ergonomia no processo de projetação de um produto de consumo proporcionará o desenvolvimento de peças mais condizentes às necessidades e atividades de cada usuário. Expor exemplos de superfícies com gradações de texturas ou ambientes em escala real, projetados como simuladores de atividades do dia-a-dia, situação já encontrada em países desenvolvidos, para a escolha de metais sanitários, ajudariam no entendimento e comparativo, frente às opções disponíveis em cada loja.

Durante toda a entrevista foi possível perceber o resgate do usuário às experiências já vivenciadas e gostos pessoais, sendo também considerado, em alguns momentos, a interferência que determinadas escolhas fazem sobre as tarefas a serem desempenhadas. Foi possível também compreender que os usuários entendem que a encolha inadequada de uma placa cerâmica pode interferir diretamente na ergonomia do ambiente construído, ou seja, na "interação do usuário, com o ambiente, o mobiliário, os objetos e a tarefa dentro de um mesmo sistema", (OLIVEIRA; MONTÁLVÃO, 2015), afetando assim o bom desempenho das atividades em seu interior. A percepção do usuário, sobre o produto e a tarefa desempenhada em determinados ambientes foram consideradas pelos consumidores, mesmo que de maneira empírica. Todos eles valeram-se do toque das mãos relacionando a sensação sentida com o toque e a possiblidade da superfície ficar escorregadia ou difícil de limpar.

\section{REFERÊNCIAS BIBLIOGRÁFICAS}

ASSOCIAÇÃO BRASILEIRA DE NORMAS TÉCNICAS. NBR 13816: Placas cerâmicas para revestimento - Terminologia. Rio de Janeiro, 1997.

ASSOCIAÇÃO NACIONAL DOS FABRICANTES DE CERÂMICA PARA REVESTIMENTOS, LOUÇAS SANITÁRIAS E CONGÊNERES - ANFACER. História da cerâmica. Disponível em: http://www.anfacer.org.br/historia-ceramica. Acesso em: 16 abr. 2017.

AZEVEDO, S.; ANDRADE, L. A. G. Habitação e poder: da Fundação da Casa Popular ao Banco Nacional Habitação [online]. Rio de Janeiro: Centro Edelstein de Pesquisas Sociais, 2011, 116 p. Disponível em: SciELO Books http://books.scielo.org.

BANKS, Marcus. Dados visuais para pesquisa qualitativa. Porto Alegre: Artmed, 2009. 


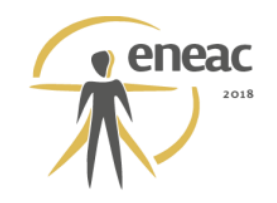

BONDUKI, N. G. Origens da habitação social no Brasil. Análise Social. Lisboa, v. 29, n. 3, p. 711 732, 1994.

BORGES, A. I. R. Metodologia de seleção de revestimentos cerâmicos - um auxiliar de projeto. Dissertação (Mestrado Integrado em Engenharia Civil) - Departamento de Engenharia Civil, Faculdade de Engenharia da Universidade do Porto, Porto, Portugal, 2008. 138 .

CAIXA ECONÔMICA FEDERAL (site oficial). Minha Casa Minha Vida. Disponível em: http://www.caixa.gov.br/voce/habitacao/minha-casa-minha-vida. Acesso em: 27 mar. 2017.

GIL, Antonio Carlos. Métodos e técnicas de pesquisa social. São Paulo: Atlas, 2008.

HOLTZBLATT, K.; BEYER, H. Contextual Design Envolved. Synthesis Lectures on HumanCentered Informatics. Morgan \& Claypool Publishers, 2014

IIDA, Itiro. Ergonomia: projeto e produção. 2. ed. São Paulo: Edgard Blücher, 2005.

MORAES, Anamaria de (Org.) Ergodesign do ambiente construído e habitado. Rio de Janeiro: iUsEr. 2004.

NORMAN, Donald. The design of every things. (e-book). New York: Basic Books, 2013.

NUNES, Denyse Brito. Espaços residenciais na percepção de alunos da APAE, Petrolina-PE. Dissertação (Mestrado em Ergonomia) - Universidade Federal de Pernambuco, Centro de Artes e Comunicação, Pernambuco, 2015. 102f.

OLIVEIRA, Gilberto R. de O.; MONT'ALVÃO, Cláudia R. Metodologias utilizadas nos estudos de Ergonomia do Ambiente Construído e uma proposta de modelagem para projetos de Design de Interiores. Estudos em Design. Revista (online). Rio de Janeiro, v.23, n.3, 2015, p. 150-165.

SANTOS, L. F. P. dos. Uma Avaliação das Políticas Federais de Habitação no Brasil 1964/2011: Déficit, Demanda e Habitação de Interesse Social. 2012.126 f. Dissertação (mestrado em economia) - Pontífica Universidade Católica de São Paulo, PUC-SP, São Paulo. 2012.

SILVA, S. M. F. da. Ladrilhos hidráulicos de São Luís: reflexos estéticos de uma época. São Luís: Secretaria de Estado da Cultura - SESC, 2005.

TAVARES, Ademario S.; ALBUQUERQUE, Luiz W. N. de; BARBOSA, André H.; VILLAROUCO, Vilma. Percepção ambiental - a importância da opinião dos usuários na geração de recomendações para projetos de ambientes construídos. In: Anais do VI Encontro Nacional de Ergonomia do Ambiente Construído \& VII Seminário Brasileiro de Acessibilidade Integral, v.2 n.7. São Paulo: Blucher, 2016.

VILLAROUCO, V.; ANDRETO, L. F. M. Avaliando desempenho de espaços de trabalho sob o enfoque da ergonomia do ambiente construído. Produção, v. 18, n. 3, p. 523-539, 2008. 